\title{
Spontaneous Bilateral Pneumothorax with Recurrent Pneumothorax: A Case Report
}

\author{
Anwar Ali Jamali ${ }^{1}$, Ghulam Mustafa Jamali' ${ }^{1}$, Bhojo Mal Tanwani², Niaz Hussain Jamali², \\ Ameer Ali Jamali ${ }^{3}$, Arslan Ahmer Rajput ${ }^{3}$ \\ ${ }^{1}$ Department of Medicine, Peoples University of Medical and Health Sciences, Nawabshah, Pakistan \\ ${ }^{2}$ Department of Physiology, Peoples University of Medical and Health Sciences, Nawabshah, Pakistan \\ ${ }^{3}$ Institute of Pharmaceutical Sciences, Peoples University of Medical and Health Sciences for Women, Nawabshah (SBA), Pakistan \\ Email: jamalianwarali@gmail.com
}

How to cite this paper: Jamali, A.A., Jamali, G.M., Tanwani, B.M., Jamali, N.H., Jamali, A.A. and Rajput, A.A. (2018) Spontaneous Bilateral Pneumothorax with Recurrent Pneumothorax: A Case Report. Case Reports in Clinical Medicine, 7, 210-219. https://doi.org/10.4236/crcm.2018.73018

Received: February 8, 2018

Accepted: March 6, 2018

Published: March 9, 2018

Copyright (c) 2018 by authors and Scientific Research Publishing Inc. This work is licensed under the Creative Commons Attribution International License (CC BY 4.0).

http://creativecommons.org/licenses/by/4.0/

(c) (i) Open Access

\begin{abstract}
Aim: To report a rare case of spontaneous bilateral pneumothorax with recurrent pneumothorax. Background: Spontaneous bilateral pneumothorax is medical and surgical emergency. It is presence of free air in the bilateral pleural spaces. It rarely occurs at any age but usually young age without apparent precipitating etiology in healthy subjects without any existing pathology. Case Report: In present case, a non smoker, uneducated, young housewife was received in emergency in critical condition and admitted in Intensive Care Unit directly, Peoples Medical university Hospital, Nawabshah, and Sindh, Pakistan. She felt difficulty in breath and after few moments she complained chest pain on right side of chest. They rushed in emergency in Peoples Medical University hospital and diagnosed as case of pneumothorax and at the same time her symptoms started worsening and she developed central cyanosis. In emergency chest X-ray was done showing bilateral pneumothorax, patient developed respiratory distress, emergency bilateral chest intubation was done and due to $\mathrm{SO}_{2}$ drop. Patient was kept on mechanical ventilation. After 24 hours she was weaned off and she was vitally in stable state and shifted in medical department and after 2 weeks she was discharged well. After 3 days of discharge she again came in emergency X-ray shown right sided recurrent pneumothorax, chest intubation done and she was referred to Oojha Institute of Chest Diseases, Karachi, Pakistan for further management and Pleurodesis. Conclusion: Bilateral spontaneous pneumothorax is medical and surgical emergency, diagnosis is thru clinical history, examination of chest and X-ray chest. Prompt diagnosis and management with chest intubation bilaterally and supportive treatment may decrease the morbidity in these critical cases.
\end{abstract}




\section{Keywords}

Bilateral Spontaneous Pneumothorax, Recurrent Pneumothorax

\section{Introduction}

Spontaneous pneumothorax common respiratory disorder, resulting in distressful respiration, can be associated with high mortality in certain situations. Spontaneous pneumothorax occurs bilaterally and at the same time accounts about 1.3 percent cases generally [1]. Regarding the statistics of pneumothorax occurs bilaterally and spontaneously it accounts about $01 \%$ of total patients with spontaneous pneumothorax [2] [3]. It is very rare that patient had developed at a time pneumothorax bilaterally and there is no instability in vitals. In single sided pneumothorax there may be from no to mild and from mild to severe life threatening complications. Sometimes these mild symptoms convert into acute emergencies with high mortality if not managed timely. Rarely there may be pneumothorax bilaterally [3]. This kind of situation occurs when there is no history of trauma or other kind of intervention history and no evident proof of physical injury. Sometimes when there are blebs in pleural surface that may rupture and result in pneumothorax spontaneously in otherwise healthy subjects before without pulmonary pathology. There may be age, gender and physique variance in patients with primary pulmonary pathology resulting in pneumothorax comparatively which occurs in old age population commonly [4]. The occurrence rate of pneumothorax occurring bilaterally and spontaneously in United States of America is 07.4 per one hundred thousand populations in males while in females it is 01.2 per one hundred thousand in women [5]. Pneumothorax occurring bilaterally and spontaneously is not a common respiratory disorder [6]. In current scenario we assessed a case report and matched the facts with the other reported cases globally through literature analyses and discussed the rare case of bilateral spontaneous pneumothorax with recurrence.

\section{Case Report}

A 27 years female, married housewife, resident of rural Nawabshah, of average height and mildly overweight presented in Emergency Unit at Medicine Department admitted in intensive care unit due to sudden onset of difficulty in breathing and pain in chest, she was in usual state of health and sitting position without any routine activity. She rushed in emergency room immediately, and chest X-ray done at bed side and surprise to see bilateral pneumothorax (Figure 1). Her condition became worse and $\mathrm{SO}_{2}$ dropped to $65 \%$. Emergency surgical unit was called for emergent bilateral chest intubation at Intensive care unit (Figure 2). Patient was kept on mechanical ventilation. This all was done on the short notice period for the saving of patient's life. She was discharged after 02 weeks in a stable state. After 25 days she again re-admitted due to chest pain and 


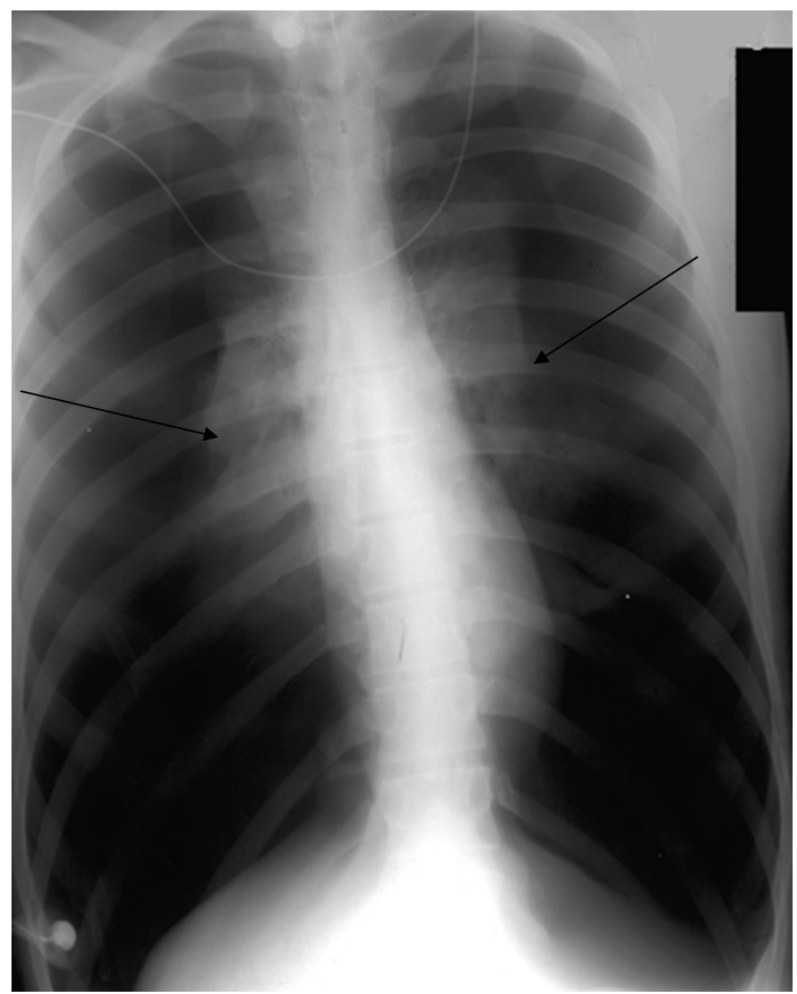

Figure 1. Spontaneous bilateral pneumothorax (arrows).

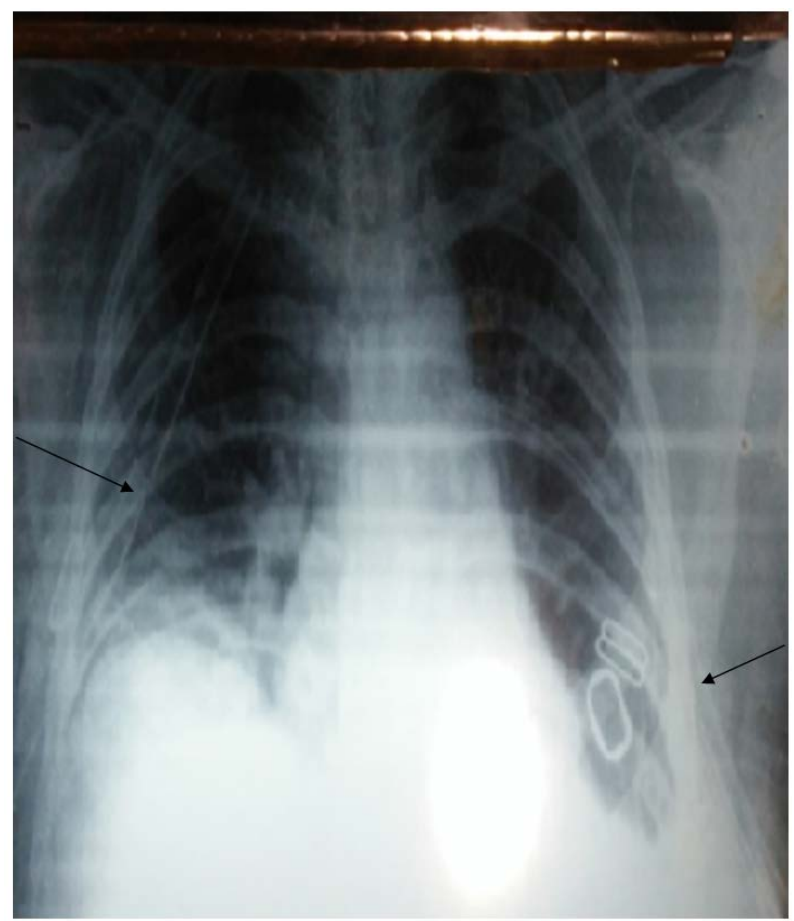

Figure 2. Bilateral pneumothorax with bilateral chest intubations (arrows).

sudden onset of shortness breath. Chest X-ray showed again right sided pneumothorax (Figure 3). Again chest intubation done in emergency and symptomatic 
treatment started (Figure 4). She was referred to Oojha institute of Chest diseases and Pleurodesis on right side was done (Figure 5). Now she is stable and performing his routine households activities without any hindrances. She

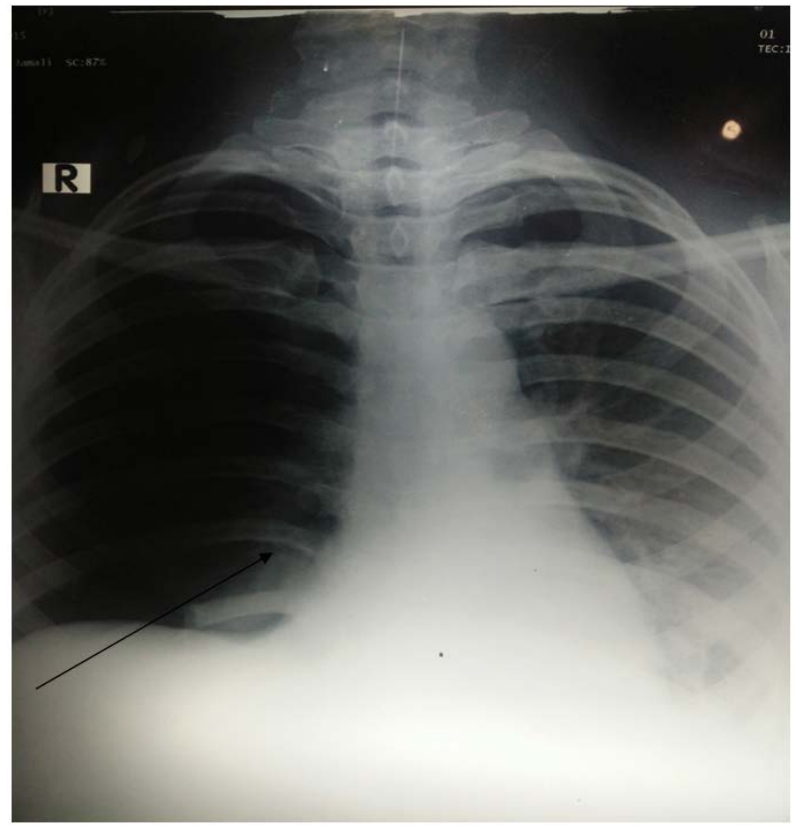

Figure 3. Recurrent right sided pneumothorax (collapse border of lung).

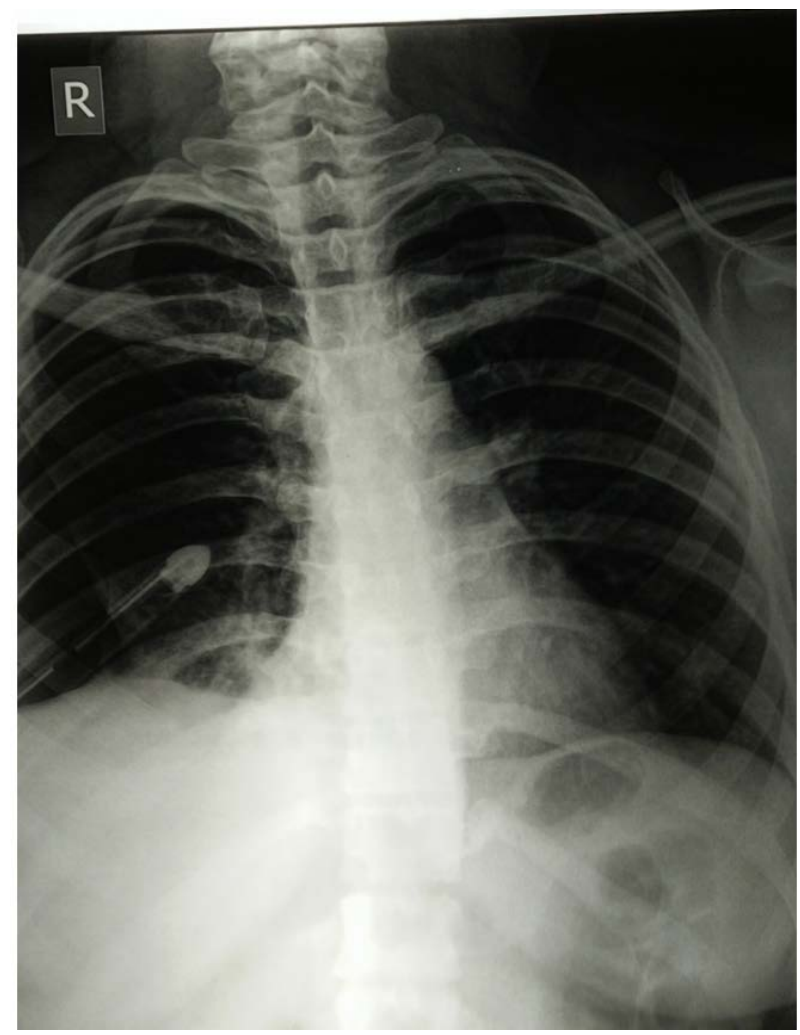

Figure 4. Right side recurrent pneumothorax. 


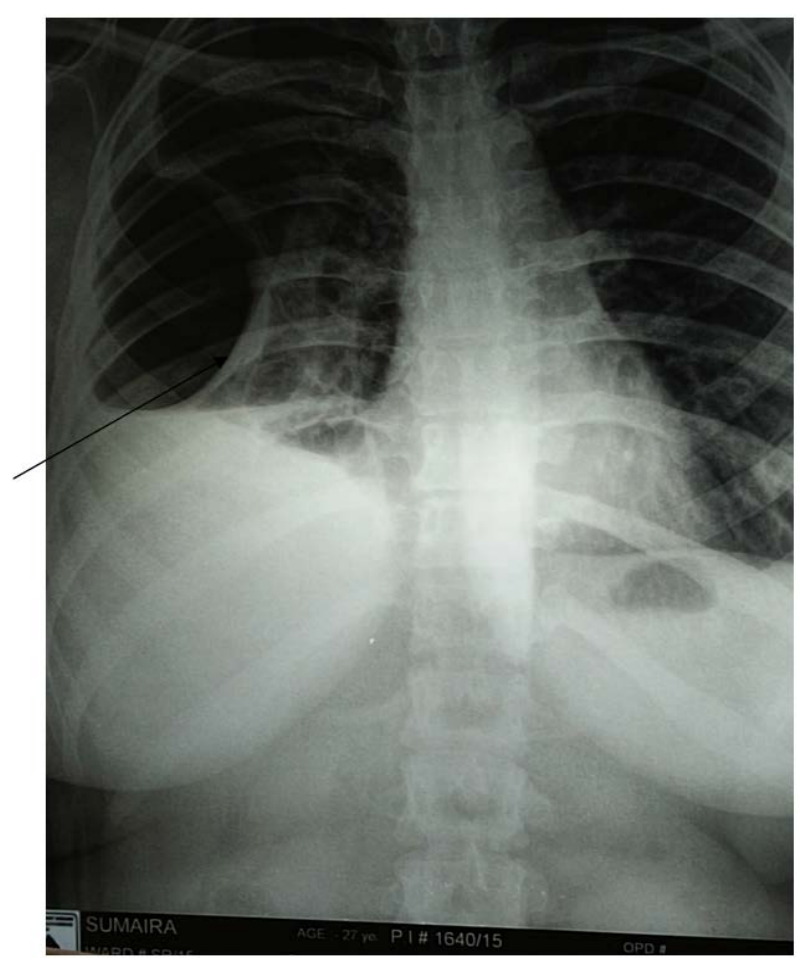

Figure 5. Persistent pneumothorax after pleurodosis (arrow).

improved vitally and after stabilization all routine necessary investigations were sent to laboratory.

Past history: no medical surgical or trauma history. Nothing important noted in history. She was not addicted, no history of allergy, blood transfusions, travel, vaccination history not clear. Her menstruation cycle was 03 days/15 days, twice in month, she has 3 children's all were quite healthy. No such a positive family history for diseases. Diet exercise history was not significant clinically.

\subsection{On Examination}

Patient was in gasping at the time of admission in ICU. Pulse was not recordable, blood pressure not recordable, cyanosis was positive, $\mathrm{SO}_{2}$ was $65 \%$ on pulse oximetery, absent breathe sounds bilaterally. After stabilization rest of other systematic examinations were performed and no abnormal finding detected.

\subsection{Chest Radiology}

$\mathrm{X}$-ray chest were advised at different stages of management, first at the time of admission (Figure 1), second after bilateral chest intubation (Figure 2), recurrent pneumothorax (Figure 3) and after Pleurodesis (Figure 4).

\subsection{Investigations}

Viral markers of HBV, HCV, and HIV were advised. HCV antibodies were positive but HCV RNA by PCR was negative. MP ICT antigen was negative. Complete blood count was within normal limits. Blood CBC: RBCs were $4.78 \mathrm{mil} / \mathrm{cumm}$, 
(Hemoglobin $12.1 \mathrm{~g} \%$, ESR $18 \mathrm{~mm} / \mathrm{hr}$, HCT 38.8\%, MCV $81.2 \mathrm{fl}, \mathrm{MCH} 28.7 \mathrm{pg}$, MCHC $35.7 \mathrm{~g} / \mathrm{dl}$ ). WBC 6800/cumm, (Neutrophil 55, Lymphocytes 42, Esinophils 02, Monocytes 01, Basophils 00). Platelets count was 240,000 cumm. Liver chemistry was within normal limits (Billurubin Total $=0.76 \mathrm{mg} \%$, Billurubin direct $=0.24 \mathrm{mg} \%$, Billurubin indirect $=0.52 \mathrm{mg} \%$, SGPT $=41.6 \mathrm{u} / \mathrm{l}$, Alkaline Phosphatse $=192.8 \mathrm{u} / \mathrm{l}, \mathrm{g}-\mathrm{GT}=17.5 \mathrm{u} / \mathrm{l})$. Antibodies against $\mathrm{H}$. pylori antigen were negative. Random Blood Sugar was $94.6 \mathrm{mg} / \mathrm{dl}$, serum Creatinine value was $0.8 \mathrm{mg} / \mathrm{dl}$, and blood urea level was $64 / \mathrm{dl}$, sodium $128 \mathrm{meq} / \mathrm{dl}$, potassium 4.2 meq/l, Chloride $72 \mathrm{mmol} / \mathrm{l}$ and $\mathrm{HCo} 325 \mathrm{mmol} / \mathrm{l}$. Prothrombin Time 14 Seconds, Control $=14$ seconds. Activated Prothrombin Time was 35 seconds, control $=35$ seconds. Mountax Test was negative.

Ultrasound: Abdomen and pelvis was normal except bilateral ovarian cysts $3.8 \times 3.2 \mathrm{~cm}$ in left and $4.4 \times 2.3 \mathrm{~cm}$ in right.

CT scan chest: Multiple axial scan of $5 \mathrm{~mm}$ thickness right sided pneumothorax (after bilateral chest intubations) left sided inflated but on right side there was still incomplete inflation with pneumothorax. No any evident pathology was reported after computed tomographic scan of chest.

Pleural Biopsy: (DOW LAB) $0.5 \times 0.5 \times 0.2 \mathrm{~cm}$ specimen submitted for biopsy in single cassette. Microscopic features: section had shown skeletal muscle fibers, single fragment shown Histiocytic Cell collections and few Foreign Body Giant Cells, no convincing Granuloma seen.

Conclusion: Skeletal muscle fibers with focal Histiocytic cell collections and foreign body giant cell reaction.

Pus Swab culture: Pus for culture from chest intubation shown no bacterial growth.

\section{Discussion}

Pneumothorax defined as clinical and radiological state in which free air accumulates in between pleural layers, resulting in difficulty in breathing and pain in chest due to incomplete or complete collapse of the lung. The X-ray chest is immediate diagnostic tool. This was also a main best initial investigation in present case. Immediate management is chest tube placement for the drainage of air and symptomatic relief. In present case emergency chest tube placement was also done. It may be Primary spontaneous pneumothorax without any apparent recurs in up to $50 \%$ of people due to bleb rupture. In spite of many investigations no final diagnosis was made in current case. Pneumothorax occurring spontaneously in patients having pulmonary pathology like obstructive airway disorders is usually due to secondary causes, it can also occur because of other pulmonary diseases like bronchial asthma, pulmonary abscesses, chronic infections like pulmonary tuberculosis, HIV associated pneumonia (Pneumocystis carani), cystic disease of lungs, acute and chronic pneumonitis, infiltrative diseases, pulmonary sarcoid disease and langerhan cell (histiocytosis) disorders. There was no possible etiology concluded in present case. Pneumothorax which is usually spontaneously secondary there is adverse clinical presentation along with outcome. 
The rate of recurrence rate is similar for both types of pneumothorax (spontaneous primary \& secondary).

Secondary spontaneous (catamenial pneumothorax) can rarely be seen within 48 hours of menstruation onset in premenopausal females and may occur in females who use estrogen after menopause. In present case menstruation history was not in favour of catamenial pneumothorax. Traumatic pneumothorax can result due to traumatic chest injury or during some medical procedures as bronchoscopy, thoracoscopy or thoracocentesis where air escapes into the pleural space. There was no such history in current scenario. Ventilators may damage lungs and can direct to pneumothorax usually in patients with COPD or ARDS. Deep-sea drivers and aeroplane pilots are more prone to develop pneumothorax due to changes in the lung pressures (barotrauma) [7]. Patient was a house lady, non smoker and no past history of smoking or other risk factor for COPD and with no sea diving or aeroplane journey. Clinical presentation in spontaneous bilateral pneumothorax is variable, these patients may present from simple mild shortness of breath to severe cardio-respiratory failure [8]. In present case the scenario was life threatening and patient received in severe respiratory distress in ICU. In present case no evidence for COPD, Pneumonia, PTB, Malignancy, Bronchial asthma, sarcoidosis, cystic fibrosis, catamonial pneumothorax, lung abscess and other evident clinical disease seen here. In this case study the menses was off 07 days before this illness. There was no history of any kind of medical instrumentation in present case. The patient was kept on mechanical ventilation after developing the bilateral spontaneous pneumothorax not before. The patient was simple house lady; no manual heavy work was noted in the history as a risk factor for pneumothorax. Pneumothorax is unilateral and uncommon [9]. Spontaneous pneumothoraxes often come across in clinical situations. SBSP is less commonly reported in literature, commonly an underlying cause in lungs can be identified such as COPD, Pulmonary Kocks or any malignancy. Rarely a communication between two pleural spaces by pleural window can be cause of SBSP [10]. Occurrence of SBSP (primary) is low from $1.4 \%$ to $7.6 \%$ and occurs in conditions requiring chest intubation or resuscitation as trauma, malignancy, iatrogenic or rarely catamenial pneumothorax, pregnancy, radiation or sarcoidosis [3] [11] [12] [13].

Clinical features may be from asymptomatic to tension pneumothorax, critically life threatening condition, unconsciousness, cyanosis and tachyarrhythmia. Management includes aspiration by needle, percutaneous drainage by catheter and thoracotomy [3] [13]. Main objective to treat this condition is to achieve the lung expansion and prevent the further recurrences. Different management options are applied that range from observation to aspiration by needle, catheter drainage percutaneous, tube thoracotomy with or without Pleurodesis, thoracotomy and VATS (Video Assisted Thoracoscopic Surgery).

Hatta et al. reported such a case in which they initially performed the bilateral tube thoracotomy followed by thoracotomy with axillary incisions on both sides with excellent results [14] [15] Bilateral pleural bleb resection through median 
sternotomy was reported by Neal et al. [16]. Recently VATS is the standard surgical approach procedure widely accepted for spontaneous pneumothorax, it causes less post operative pain and smaller cosmetic scar in comparison to open thoracotomy. The initial basic treatment is the chest drainage [17]. Air leakage is mostly halted up to $52 \%$ within 05 hours and up to $82 \%$ in the 48 hours with tube Thoracoscopy [18]. In prolonged air leakage which remains for more than 07 - 10 days is indication for surgery even in first attack, some studies reported to delay surgery if air leakage persist for 15 days [19].

In the presenting case CT chest did not reveal any abnormality. Left lung completely re-expanded and there was partial re-expansion of right lung. This patient underwent surgical Thoracoscopy with right sided chemical Pleurodesis and there were no significant post procedure pulmonary edema.

No etiology was concluded in this case, she was not pregnant at time of illness, no history of chest abdomen trauma, thrusting, and no weight lifting before or at the time of illness.

In present case Computed tomography of the chest revealed no significant pathology. Right sided chest Thoracoscopy with Pleurodesis was done and no immediate or late complication of intervention seen, especially edema due to re-expanded lung tissues. Post procedure X-ray chest shown partial remnants of pneumothorax on right side of chest. In present case the above treatment options were used chest intubation in first episode and Thoracoscopy and Pleurodesis in the recurrent pneumothorax. Although the reason of recurrence was not determined in our case but major steps were to control the situation. From the facts of above case scenario it is evident that in early management placement of chest tube is vital step of management to save the life of patients in bilateral pneumothorax. Efforts should be taken to assess the etiology of the condition. If cause is evident through investigations, steps should be taken to treat it properly. If there is risk of recurrence so the Pleurodesis option should be available as alternative part of management as it was done in this present case. In current case emergency steps were taken for chest intubation and life of patient was secured. No exact etiology was detected in our case. CT scan of chest was almost normal. Thoracoscopy had done no pathology seen. Pleural biopsy was not conclusive. There was incomplete expansion of right lung even after trial of Pleurodesis. No proper diagnosis was made till Pleurodesis. Now the patient is in stable state and living normal limited routine life activities. Present case was managed with initial bilateral chest intubations and broad spectrum antibiotics and lastly on the pleurodesis along with symptomatic treatment. She was advised for follow-up properly. Now she is stable passing her routine life with precautions like not to lift weight, avoid constipation and proper treatment of chest infection if it occurs etc.

\section{Conclusion}

Spontaneous Bilateral Pneumothorax, a medical and surgical life-threatening emergency, early diagnosis and emergent management, is crucial step to save the lives of patients and thereby reduces the morbidity and mortality. 


\section{References}

[1] Aydin, Y., Turkyilmaz, A., İntepe, Y.S. and Eroglu, A. (2010) Simultaneous Bilateral Spontaneous Pneumothorax: A Rare Emergency Clinical Condition. The Eurasian Journal of Medicine, 42, 5-8. https://doi.org/10.5152/eajm.2010.02

[2] Wang, H. and Nugent, W.C. (2010) Cough-Induced Bilateral Spontaneous Pneumothorax. The Annals of Thoracic Surgery, 90, 1363-1365.

https://doi.org/10.1016/j.athoracsur.2010.04.024

[3] Lee, S.C., Cheng, Y.L., Huang, C.W., et al. (2008) Simultaneous Bilateral Primary Spontaneous Pneumothorax. Respirology, 13, 145-148.

https://www.ncbi.nlm.nih.gov/pubmed/18197926

[4] Light, R.W. (1994) Pneumothorax. In: Murray, J.F., Ed., Textbook of Respiratory Medicine, Vol. 2. WB Saunders, Philadelphia, 2193-2208.

[5] Melton III, L.J., Helper, N.G.G. and Offord, K.P. (1979) Incidence of Spontaneous Pneumothorax in Olmsted County, Minesota: 1950 to 1974. The American Review of Respiratory Disease, 120, 1379-1381. https://www.ncbi.nlm.nih.gov/pubmed/517861

[6] Graf-Deuel, E. and Knoblauch, A. (1994) Simultaneous Bilateral Spontaneous Pneumothorax. Chest, 105, 1142-1146. https://doi.org/10.1378/chest.105.4.1142

[7] Richard, W.L. (2017) Pneumothorax. MSD Manual. Last Full Review. Merck Sharp \& Dohme Corp., a subsidiary of Merck \& Co., Inc., Kenilworth.

[8] Sayar, A., Turna, A., Metin, M., Kucukyagci, N., Solak, O. and Gurses, A. (2004) Simultaneous Bilateral Spontaneous Pneumothorax, Report of 12 Cases and Review of Literature. Acta Chirurgica Belgica, 104, 572-576. https://doi.org/10.1080/00015458.2004.11679617

[9] Gupta, K.B., Manchanda, M. and Kaur, P. (2006) Bilateral Spontaneous Pneumothorax in Silicosis. Indian Journal of Chest Diseases and Allied Sciences, 48, 201-203. https://www.ncbi.nlm.nih.gov/pubmed/18610678

[10] Yamada, S., Yoshino, K. and Inoue, H. (2008) Simultaneous Bilateral Spontaneous Pneumothorax with Pleural Window Communicating with Bilateral Pleural Spaces. The Annals of Thoracic Surgery, 85, 1434-1436. https://doi.org/10.1016/j.athoracsur.2007.10.033

[11] Rivas de Andrés, J.J., Jiménez López, M.F., Molins López-Rodó, L., et al. (2008) Guideline for the Diagnosis and Treatment of Spontanesous Pneumothorax. Archivos de Bronconeumologia, 44, 437-448. https://www.ncbi.nlm.nih.gov/pubmed/18775256

[12] Kim, E.S., Sohn, S.T. and Kang, J.Y. (2006) Simultaneous Bilateral Spontaneous Pneumothorax. The Korean Journal of Thoracic and Cardiovascular Surgery, 39, 475-478.

[13] Shields, T.W. (2005) General Thoracic Surgery. 6th Edition, Williams \& Wilkins, New York, 794-805.

[14] Hatta, T., Mastuda, S., Kuris, S., et al. (1993) A Case of Simultaneous Bilateral Pneumothorax. Kyobu Geka, 46, 287-289. https://www.ncbi.nlm.nih.gov/pubmed/8468850

[15] Ohara, K., Yamazaki, T., Sakaguchi, K., Nakayama, M. and Kobayashi, A. (1994) A Case of Simultaneous Bilateral Pneumothorax. Kyobu Geka, 47, 1110-1111. https://www.ncbi.nlm.nih.gov/pubmed/7830366

[16] Ohara, K., Yamazaki, T., Sakaguchi, K., Nakayama, M. and Kobayashi, A. (1979) Bilateral Bleb Excision through Median Sternotomy. The American Journal of Surgery, 138, 794-797. https://doi.org/10.1016/0002-9610(79)90298-8 
[17] Eroglu, A., Turkyilmaz, A., Aydin, Y., Erdem, A.F., Tokur, M. and Karaoglanoglu, N. (2007) Treatment of Secondary Spontaneous Pneumothorax: 100-Patient Experience. EAJM, 39, 97-102.

[18] Baumann, M.H. and Strange, C. (1997) Treatment of Spontaneous Pneumothorax: A More Aggressive Approach? Chest, 112, 789-804. https://doi.org/10.1378/chest.112.3.789

[19] Chee, C.B., Abisheganaden, J., Yeo, J.K., et al. (1998) Persistant Air-Leak in Spontaneous Pneumothorax Clinical Course and Outcome. Respiratory Medicine, 92, 757-761. https://doi.org/10.1016/S0954-6111(98)90008-7 